\title{
Inovações Vistas pelas Patentes: Exigências Frente às Novas Funções das Universidades*
}

\section{Heiko Haase}

Faculdade de Ciências Econômicas - Technische Universität Ilmenau

\section{Eliane Cristina de Araújo}

Faculdades do Centro do Paraná - UEM

Joilson Dias

Departamento de Economia - UEM

\section{RESUMO}

O presente artigo analisa a importância das patentes para o meio acadêmico no Brasil, referindo-se à literatura sobre intellectual property right theory. Inicialmente, são abordadas algumas questôes teóricas relativas às patentes e, em segui$\mathrm{da}$, às leis que regem a operacionalização desse mecanismo nas universidades no Brasil, Estados Unidos e Alemanha, evidenciando alguns dados a esse respeito. $\mathrm{O}$ artigo apresenta determinadas influências das patentes sobre as universidades e o setor privado, e algumas sugestões de políticas são inferidas, como: $i$ ) melhoria da infra-estrutura de informações sobre patentes e sua transposição ao mercado; ii) maior incorporação dos pesquisadores nas estratégias de exploração comercial; iii) orientação das atividades de pesquisa à demanda do mercado; iv) cooperação de empresas em áreas de pesquisas intensivas em P\&D; $v$ ) concessão de licenças

\footnotetext{
Os autores agradecem os comentários dos pareceristas anônimos da RBI. Eventuais falhas remanescentes são de nossa exclusiva responsabilidade.
} 
exclusivas às empresas; e vi) otimização da comercialização das patentes através de sistemas flexíveis de estímulos e redes de contato.

Palavras-Chave | Patentes; Propriedade Intelectual; Inovaçōes; Transferência de Conhecimentos; Universidades

Códigos JEL | M 13; O 31; O 34

\section{ABSTRACT}

The article analyzes the importance of patents for Brazilian universities with reference to the literature on the intellectual property right theory. It deals initially with theoretical questions regarding patents. Subsequently, the paper shows the current legislations of Brazil, the USA and Germany as well as empirical information on university patents. Furthermore, the article refers to the impact of these patents on universities and on the private sector. Finally, it makes the following suggestions: $i$ ) improvement of infrastructures on patent information and transfer to the market; ii) major inclusion of researchers and professors in commercial exploitation strategies; iii) orientation of research activities to the market demand; $i v$ ) cooperation with private sector in research fields with intensive $\mathrm{R} \& \mathrm{D} ; v)$ granting of exclusive licenses to private businesses; and $v i$ ) optimization of patent commercialization installing flexible systems of incentives and networks.

KeYwords I Patents; Intellectual Property; Innovations; Transfer of Knowledge; Universities

JEL Codes I M 13; O 31; O 34 


\section{Introdução}

Diversas e profundas mudanças vêm ocorrendo no cenário econômico mundial que afetam tanto países desenvolvidos como países em processo de desenvolvimento. Entre estas, se destacam a globalização dos mercados, a revolução científica e tecnológica e o desenvolvimento dos meios de comunicação. Esses fenômenos aumentaram a competitividade entre empresas e a busca por excelência de produtos e processos, que estimularam fortemente a criação de inovações tecnológicas não só no meio empresarial, mas também no meio acadêmico. Como conseqüência, os setores tradicionais estão se transformado profundamente mediante a incorporação de novas tecnologias, simultaneamente a uma maior orientação para as áreas voltadas à geração e aplicação de resultados de pesquisas inovadoras. No marco dessas transformações, o conhecimento junta-se aos tradicionais fatores de produção, construindo uma "sociedade do conhecimento".

Essa adaptação, além de ter se tornado fundamental para o setor privado, passou a influenciar o papel das universidades. Sua função, além do ensino, estende-se também à produção e à divulgação de resultados de pesquisa básica e aplicada. Por isso, as universidades são consideradas tradicionalmente como fonte principal de inovações e mudança tecnológica. A literatura econômica atual a esse respeito está enfocada nos spillovers da pesquisa acadêmica (Romer, 1986; Jaffe, 1989) de fundamental importância por aumentarem a produtividade do setor privado e a produtividade total dos fatores (Adams, 1990).

Nos últimos anos, esses efeitos têm se apresentado por meio da comercialização dos conhecimentos gerados nas universidades, o que torna a proteção jurídica dos resultados das pesquisas e sua rápida transferência para o setor privado uma importante função adicional das universidades. Dentro desse contexto, as patentes têm ganhado grande notoriedade para a configuração de políticas públicas nas discussões sobre o papel das universidades em um sistema caracterizado por inovações. Como resultado desse processo, vários países, entre eles o Brasil, adotaram novas legislações que influenciaram a função das instituiçôes acadêmicas no que se refere à proteção do conhecimento.

Assim sendo, este artigo tem como objetivo analisar a importância das patentes para o meio acadêmico no Brasil, considerando as novas funções das univer- 
sidades. Para tanto, o trabalho trata inicialmente das questôes teóricas sobre as patentes. Em seguida, discute as legislações em vigor, assim como as informações empíricas referentes às patentes no meio acadêmico. Dando continuidade, o artigo mostra os impactos das patentes originadas nas universidades sobre estas e sobre o setor privado, o que possibilitará apresentar sugestôes de políticas voltadas para as universidades que, devido ao caráter altamente exploratório do trabalho, podem ser somente sugestivas.

$\mathrm{O}$ artigo está inserido basicamente dentro da literatura conhecida como intellectual property right theory (Palmer, 1989; Audretsch, 1995; Foray, 1995; Towse \& Holzhauer, 2002) e está destinado a ampliar a crescente literatura sobre os impactos econômicos do patenteamento no meio acadêmico (Adams 1990; Henderson et al., 1998; Mowery et al., 2001, 2002; Thursby \& Kemp, 2002; Link et al., 2003; Shane, 2004). No entanto, traz como diferencial em relação aos trabalhos anteriormente citados o fato de enfatizar o caso brasileiro.

\section{Questões teóricas relativas à propriedade intelectual}

As considerações seguintes representam brevemente o fundamento teórico que descreve a função das patentes e seu impacto no sistema econômico, apresentando a teoria dos estímulos, bem como as considerações dinâmicas acerca das patentes.

\subsection{Definições}

À primeira vista, embora a definição de "conhecimento" pareça simples, a sua conceitualização formal torna-se problemática. O termo "conhecimento" pode ser definido como um processo dinâmico e absolutamente pessoal, pois representa as habilidades de um indivíduo em determinada área (Polanyi, 1962:17). O conhecimento, portanto, pode ser concebido como um processo cognitivo que concede ao seu possuidor a capacidade de realizar ações intelectuais ou físicas. A sua base configura as informações que podem ser caracterizadas como dados estruturados e formatados, sendo que estes permanecem passivos e incertos sem os adequados processamentos e interpretaçôes. Logo, o conhecimento consiste em uma combinação sistemática e sustentável de 
informações, resultado de um processo dedutivo em que os conhecimentos preexistentes associam-se cumulativamente a julgamentos e classificaçôes individuais de novas informaçôes.

Se o conhecimento é a solução inicial para um problema técnico, econômico, organizacional ou social, denomina-se "invenção", que pode ser rigorosamente planejada ou ocorrer por acaso. Se essa invenção é composta por algumas características adicionais, tais como pertencer a um setor voltado para a tecnologia, mostrar-se como uma novidade, representar um processo realmente inovador e ter utilidade prática, é possível classificá-la como uma invenção no âmbito das leis referentes às patentes. É evidente que apenas uma pequena proporção de todos os conhecimentos gerados obedecem a essas exigências; tal fato pode ser comprovado quando se analisa o total das aplicações de patentes, reforçado, ainda, pelo número menor das patentes concedidas.

Apesar de o estoque de conhecimento contribuir positivamente para a concepção de novo conhecimento, a criação de valores econômicos só ocorre a partir do momento em que as invenções são transformadas em produtos e serviços comercializáveis no mercado, os quais, ao se manifestar de forma exitosa, são denominados "inovação" (Schumpeter, 1961:91 f.).

De acordo com a Figura 1 e tomando como exemplo as patentes, é possível verificar que existe uma relação inversa entre a criação de valores econômicos e a quantidade dos resultados de pesquisa. Isto pressupõe uma quantidade suficientemente elevada de informações e conhecimentos para a geração de inovações (Latini, 2003:7; Feldman et al., 2002:108). Além disso, os resultados de pesquisa por si próprios possuem pequena capacidade para a criação de valores econômicos em virtude dos investimentos que ainda são necessários para transformá-los em novos produtos e serviços comercializáveis, sobretudo no caso de inovaçóes. Para incentivar e aumentar as possibilidades da concretização desses investimentos existem mecanismos de proteção que serão objeto de estudo do próximo item.

\subsection{Instrumentos informais e formais}

O conhecimento possui algumas características específicas que o diferencia dos demais fatores de produção, entre as quais se destacam sua intangibilidade 
FIGURA 1

A relação entre conhecimento e inovação à criação de valores econômicos

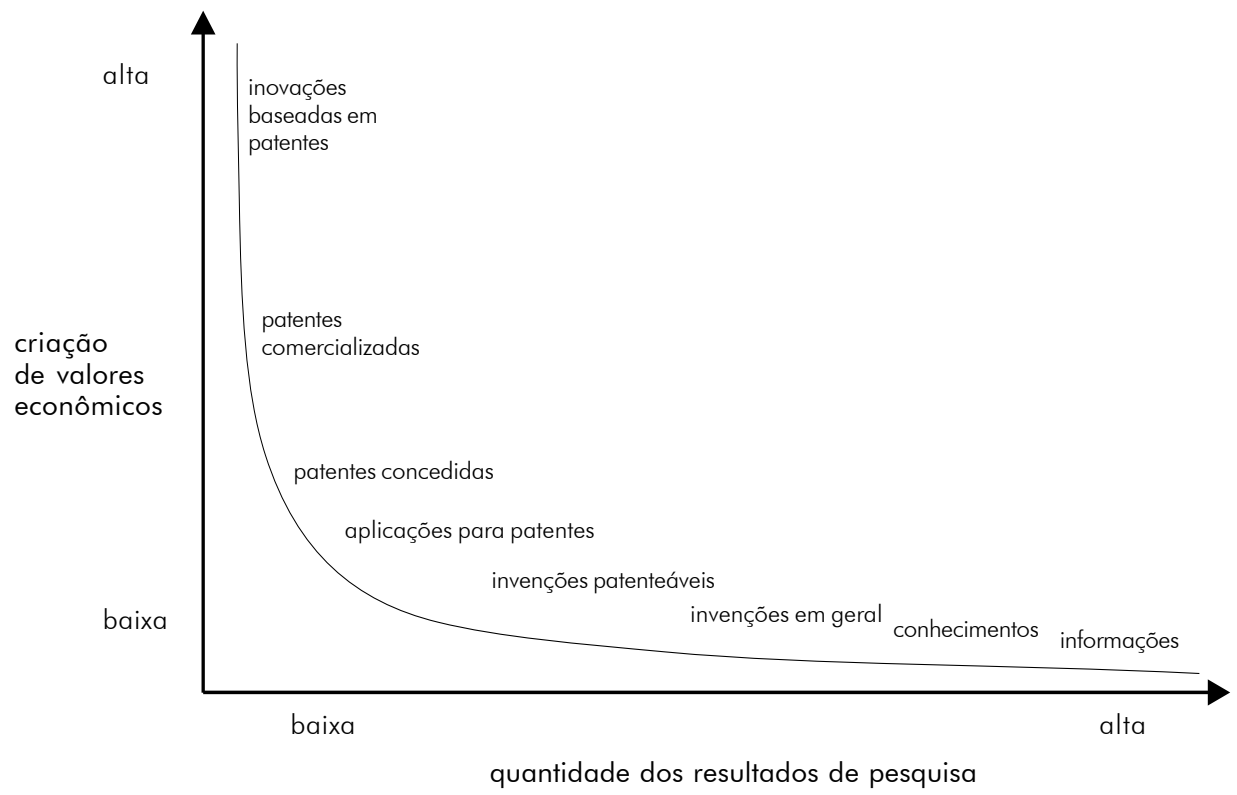

Fonte: elaboração própria.

e capacidade de não possuir vínculos a determinado lugar. Conforme Polanyi (1962), o conhecimento humano é classificado em conhecimento explícito e tácito. O primeiro permite a representação escrita e é facilmente registrado, sistematizado e comunicado, podendo ser formalmente transmitido as outras pessoas. Ao contrário, o conhecimento tácito retrata as experiências individuais dos agentes e é constituído por elementos intangíveis como instituições, crenças, emoções e habilidades, o que dificulta sua representação em linguagem formal. Ambos os conhecimentos, contudo, são unidades que se completam e a interação entre eles condiciona a dinâmica da criação do total de conhecimento.

Mesmo sendo tácito e idiossincrático, o conhecimento pode ser transferido ou reproduzido quase sem custos, em um tempo extremamente rápido e com alcance ilimitado. Isto decorre do fato de que a maior parte do conhecimento existente, especialmente no meio acadêmico, é publicamente disponível e as 
infrações da propriedade intelectual ainda não são consideradas com devida relevância. Por conseguinte, as características inerentes ao conhecimento fazem com que este se torne extremamente vulnerável à exploração por parte dos free riders.

Diante disso a estimulação e a manutenção de investimentos em atividades de Pesquisa e Desenvolvimento (P\&D) requerem uma ampla disposição de medidas que objetivem conservar os rendimentos originados pela transposição dos conhecimentos ao sistema econômico, tendo em vista o montante significativo de recursos necessários para a sua concepção. Tais medidas são representadas por mecanismos de proteção, que podem ser classificados como informais e formais. No que se refere aos primeiros, os mais destacados são i) a elaboração complexa para que o entendimento seja dificultado; ii) a manutenção secreta dos conhecimentos gerados; e iii) a utilização do lead time como monopólio temporário decorrente da rápida entrada de uma empresa no mercado (Grupp et al., 2003:64).

No entanto, tais medidas mostram-se pouco eficientes para proteger as inovações baseadas em conhecimento, o que ocorre, por um lado, porque a manutenção secreta dos conhecimentos gerados somente é possível até a inserção do produto ou serviço no mercado e, por outro, devido ao curto ciclo da inovação e da velocidade na qual os competidores no mercado são capazes de realizar uma imitação, tornando a vantagem do lead time modesta.

Com relação aos mecanismos formais, estes representam direitos exclusivos, legalmente garantidos e com prazos limitados, que conferem ao seu proprietário uma série de possibilidades para impedir e punir o uso indevido do conhecimento protegido. Como exemplo, pode-se mencionar os direitos autorais (copyright), patentes, modelos de utilidade, desenhos industriais, entre outros. Esses instrumentos encontram-se representados na Figura 2.

Entre os instrumentos formais, as patentes têm-se destacado em discussões recentes no tocante à proteção das atividades inovadoras no meio acadêmico. Isto se deve a uma série de características inerentes apresentadas por estas. Uma delas é que as patentes são caracterizadas pela "livre transferibilidade", constituindo-se em um mecanismo único e altamente visível de transferência de conhecimento tecnológico ao setor privado (Basberg, 1987). O conceito da "livre transferibilidade" relaciona-se ao fato de que as patentes representam um título legal que pode estar sujeito tanto ao licenciamento como também à venda 
FIGURA 2

Instrumentos informais e formais de proteção de conhecimento

instrumentos de proteção do conhecimento
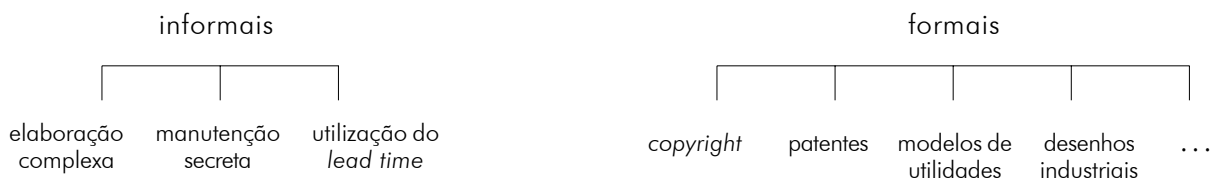

Fonte: elaboração própria.

e à avaliação individual que, ao conferirem exclusividades temporárias de comercialização, permitem aos produtores recuperarem os custos do investimento em P\&D e auferirem lucros, o que torna possível sua utilização como garantia de crédito, capital próprio e participações em empresas.

Outra característica se relaciona ao fato de que a patente representa um mecanismo de proteção legal para a propriedade intelectual que é clássico, tradicionalmente existente e internacionalmente aceito, constituindo-se na forma de proteção mais difundida de inovações em nível internacional. ${ }^{1}$

Um terceiro aspecto concernente as patentes é que, por sua definição, estas representam um monopólio jurídico, ou seja, um conjunto de direitos exclusivos e abrangentes que criam títulos legais para um período máximo de 20 anos. São, portanto, consideradas como o meio mais eficiente frente aos demais mecanismos para a proteção de conhecimento, por garantirem proteção jurídica contra imitação e violação do conhecimento tecnológico (Audretsch, 1995:42).

Pode-se ressaltar ainda, que o sistema de patentes proporciona uma maior eficiência dinâmica, ao estimular investimentos em P\&D e, conseqüentemente, o progresso técnico, embora isto ocorra em detrimento da eficiência estática, que surge pelos custos associados ao monopólio concebido pela patente (Arrow, 1962).

\footnotetext{
As estatísticas dos escritórios das patentes, como do European Patent Office, do U.S. Patent and Trademark Office, assim
} como do Instituto Nacional da Propriedade Industrial - INPI, demonstram claramente essa tendência. 
Por fim, cabe destacar o efeito da ampliação da reputação do titular da patente e a comprovação da existência de resultados benéficos dos spillovers que o uso das patentes no meio acadêmico trazem para a sociedade como um todo (Jaffe, 1989; Acs et al., 1994).

Enfatizada a importância das patentes, as considerações seguintes estarão voltadas exclusivamente para a análise desse mecanismo, tendo em vista que a literatura econômica aponta diversas explicaçôes teóricas que buscam justificar a existência de patentes na economia.

Evidentemente, não se tem a pretensão de, nestas breves linhas, esgotar toda a literatura existente sobre o assunto, mas somente mencionar as teorias consideradas mais tradicionais para explicar a importância do mecanismo de patentes para o sistema econômico. O trabalho pioneiro na classificação dessas teorias foi desenvolvido por Machlup (1961). Para este autor, a justificativa para a existência de patentes pode ser estabelecida em quatro diferentes vertentes $: i$ ) a Teoria da Propriedade, que descreve o direito natural do inventor de tomar posse da sua invenção; ii) a Teoria da Remuneração, que parte da idéia de recompensar o inventor por ter contribuído ao progresso tecnológico e, conseqüentemente, pelo serviço prestado à sociedade; iii) a Teoria do Contrato, também denominada Teoria da Publicação, que concebe as patentes como compensação ao inventor em troca da publicação de uma nova solução de um problema técnico preexistente; e iv) a Teoria dos Estímulos, que considera as patentes como um instrumento jurídico para fomentar e incentivar o progresso econômico e tecnológico.

No contexto econômico atual, além das classificações anteriormente mencionadas, outra teoria que tem se destacado é a denominada Intellectual Property Rights (Palmer, 1989; Audretsch, 1995; Foray, 1995; Towse \& Holzhauer, 2002), na qual o critério da exclusividade dos direitos exerce uma função central, possibilitando ao indivíduo dispor de sua propriedade (material e imaterial) e privar outros agentes do uso de seu bem, o que é inteiramente respaldado pela sociedade.

Essas justificativas teóricas para o estabelecimento de patentes não devem ser excludentes, mas utilizadas de forma conjunta. Neste sentido, a posse de uma patente traz alguns efeitos para seu titular, que pode, através dessa concessão, regular a oferta de seu conhecimento patenteado no mercado e, ao mesmo tempo, assegurar e estabilizar de forma efetiva os lucros dos seus capitais investidos nas 
atividades de inovação, evitando a atuação de free rider (Audretsch, 1995:38-40). Isto gera estímulos para investimentos futuros em $\mathrm{P} \& \mathrm{D}$, o que possibilita a criação de novos conhecimentos que sejam patenteáveis. Assim, o inventor é estimulado a realizar o patenteamento até o ponto em que os lucros esperados, que são a diferença entre o valor das receitas esperadas e dos custos originados por esse processo, sejam positivos.

Do anteriormente exposto, o patenteamento pode ser interpretado como um processo de privilegiamento posterior às atividades inventoras, no qual uma determinada parte das externalidades causadas pela invenção é internalizada pelos inventores (Palmer, 1989:273-277). As patentes, por assegurarem acesso restrito, possuem um efeito estimulador de investimentos privados por meio da exploração produtiva da invenção, os quais, sem a proteção legal, não teriam sido realizados. Assim, supondo-se mercados que funcionem eficientemente, a adequada utilização das patentes leva, no longo prazo, à exploração adequada do conhecimento, estímulos ao progresso tecnológico e ao crescimento econômico.

Para explicar os efeitos que as patentes exercem sobre o sistema econômico, existem considerações estáticas e dinâmicas. Com relação às primeiras, a análise é feita utilizando uma comparação entre um mercado de concorrência perfeita, caracterizada por produtos homogêneos, e uma situação de monopólio, que surge a partir da concessão das patentes. Nesse caso, os efeitos positivos das patentes podem ser contrastados com as perdas de bem-estar geradas pelo monopólio, denominadas deadweight loss of monopoly, que ocorrem devido à concessão exclusiva dos direitos da inovação ao titular da patente. Entretanto, as consideraçôes puramente estáticas sobre a proteção conferida pelas patentes apresentam pouca relevância para explicar os reais impulsos desse processo ao crescimento econômico, o que realça a necessidade de uma análise dinâmica (Audretsch, 1995:55).

Devido a suas características tecnológicas, as inovações patenteadas por uma empresa apresentam uma vantagem ímpar em relação aos produtos ofertados no mercado pelas concorrentes. Todavia, as empresas concorrentes, potenciais inovadoras no âmbito das considerações dinâmicas, dispóem da possibilidade de entrar em concorrência com o possuidor dos direitos conferidos pela patente por meio de tecnologias praticamente equivalentes, ou também utilizar o conhecimento já patenteado como base para realizar suas próprias atividades de P\&D, gerando, assim, produtos ainda mais sofisticados (Klemperer, 1990:127). 
Isto deixa o titular de uma patente exposto a uma situação de competição, o que influencia a sua política de preço-quantidade orientada ao mercado, obrigando-o a realizar continuamente atividades próprias de P\&D. A essa situação associa-se o fato de que as anualidades pagas para a manutenção de patentes sobem progressivamente, fazendo com que estas tornem-se viáveis apenas quando a possibilidade de auferir lucros marginais positivos seja estabelecida. Em decorrência disso, a duração máxima das patentes é utilizada integralmente somente em alguns casos.

A essa crítica da análise estática das patentes orientada pela oferta confronta-se uma outra, voltada para a demanda (Towse \& Holzhauer, 2002:xvii f.). Com a exploração comercial de novas tecnologias, originam-se, especialmente na fase de abertura de um novo mercado com número crescente de usuários, efeitos em cadeia sobre os demandantes. Neste contexto, as vantagens geradas pelo emprego da tecnologia inovadora decorrem de externalidades positivas que dependem não só da abrangência de sua utilização, mas também da maneira como esta pode ser empregada por outros demandantes. Assim sendo, as patentes, apesar de se constituírem em um monopólio temporariamente limitado, propiciam aumento do número de usuários da tecnologia inovadora, o que por sua vez criará efeitos em cadeia que ampliarão o bem-estar da economia como um todo (Katz \& Shapiro, 1985, 1986). Não obstante, como tais efeitos perdem força ao longo do tempo haverá, conseqüentemente, redução dos efeitos positivos do patenteamento sobre o bem-estar.

Em contrapartida, os efeitos positivos que o estabelecimento de um sistema de patentes traz sobre o bem-estar devem ser confrontados com os custos de transação originados por esse processo. Estes são compostos basicamente por quatro elementos. O primeiro tipo refere-se às taxas que são cobradas para a aplicação, tradução (caso seja necessário), concessão e manutenção da patente. $\mathrm{O}$ segundo diz respeito aos gastos relacionados às eventuais concessões de licenças. Já o terceiro engloba os recursos empregados à contínua supervisão do mercado no que tange ao desenvolvimento de tecnologias similares e às infrações cometidas contra a patente. Por fim, o quarto custo está relacionado à imposição jurídica dos direitos conferidos pela patente. Estes dois últimos, além de serem imprevisíveis e voláteis, podem superar facilmente os custos diretos considerados no primeiro e segundo casos. Tais custos de transação, de forma geral, exercem influência não 
somente sobre a eficiência do sistema de patentes, mas também sobre a decisão de efetuar o patenteamento e na imposição dos direitos conferidos.

Isto se dá porque é necessária uma ponderação entre os custos que restringem o acesso ao conhecimento e o aumento do bem-estar gerado pelos maiores estímulos às atividades inovadoras (Landes \& Posner, 1989:326). Essa ponderação por parte do titular potencial da patente é influenciada não apenas pelas expectativas referentes à exploração comercial desta, mas também devido à avaliação da posição de monopólio que esta confere. Tal posição monopolista depende do efeito das barreiras geradas pela proteção da patente, de seu alcance e de sua duração (Towse \& Holzhauer, 2002:xii). Sendo assim, patentes que apresentam um limitado efeito de barreira, alcance restrito e curta duração dispõem somente de uma exclusividade reduzida, o que enfraquece a posição jurídica de seu titular (Audretsch, 1995:57).

Esse alcance limitado, porém, favorece processos de inovações alternativos, os quais não aconteceriam no caso de um alcance mais abrangente (Merges \& Nelson, 1990:916) que levaria, em conseqüência, a uma maior difusão dos conhecimentos tecnológicos. Analogamente ao efeito de barreiras limitado, uma curta duração da patente induz a maiores atividades de inovaçóes por parte de outros participantes do mercado. Pode-se concluir, portanto, que um alcance restrito e uma curta duração da patente são fundamentais para estimular altas taxas de inovação em áreas de patenteamento cujo ciclo de vida do produto é rápido. Essa exclusividade restrita não deve desestimular a geração do conhecimento pelos inovadores para não haver a interrupção do processo inovativo.

\section{Análise de legislações e dados empíricos sobre patentes}

Após o esclarecimento de questôes teóricas e precedendo à aplicabilidade desses fundamentos às patentes originadas no meio acadêmico, é necessário ressaltar a relação existente entre patentes e universidades em alguns países para que, posteriormente, seja possível direcionar as políticas a esse respeito. Desta forma, será analisada a seguir a legislação no Brasil, acompanhada de dados empíricos. Apesar do reconhecimento de que estudos relativos a países igualmente emergentes como o Brasil trariam importantes implicações, optou-se por avaliar a situação nos Estados Unidos e na Alemanha, tendo em vista que ambos estão entre 
os países mais desenvolvidos na área de proteção da propriedade intelectual, cujas experiências poderão respaldar as sugestōes voltadas para o Brasil.

\subsection{Brasil}

A discussão sobre a relação entre patentes e universidades é ainda recente no Brasil. Apesar de o tema estar sendo adequadamente tratado por diversas instituições de ensino e pesquisa: Unicamp (Universidade Estadual de Campinas), USP (Universidade de São Paulo), Embrapa (Empresa Brasileira de Pesquisa Agropecuária) e Fiocruz (Fundação Oswaldo Cruz), há uma certa heterogeneidade no que se refere a esse tratamento.

Não se pode negar que essa temática venha recebendo importância crescente na economia brasileira, o que tem influenciando, em grande medida, a sua institucionalidade no País. Tal fato pode ser ilustrado pelas alterações introduzidas na legislação de proteção à propriedade intelectual, nos fóruns de capacitação e troca de experiências, e nos núcleos de apoio à proteção e comercialização de inovações.

Em se tratando da legislação, destaca-se inicialmente a criação da Lei no ${ }^{\circ}$ 9.279, de 14 de maio de 1996, que alterou profundamente a legislação patentária, regulando as obrigaçôes referentes à propriedade industrial no País e compreendendo as diferentes formas de proteção, os procedimentos de depósito, as condiçôes para obtenção dos privilégios e os limites impostos aos mesmos.

No que tange ao tratamento da questão do patenteamento dos resultados de pesquisa gerados nas universidades, este passou a ser realizado a partir da entrada em vigor do Decreto oㅡ 2.553, de 16 de abril de 1998, que regulamenta artigos da lei relativos a patentes, assim como o compartilhamento devido a pesquisadores de instituições públicas. A partir desse decreto, a todo servidor da administração pública (direta, indireta e fundacional) que desenvolver uma invenção suscetível ao patenteamento será assegurado, a título de incentivo, durante toda a vigência da patente ou do registro, a premiação de parcela do valor das vantagens auferidas pelo órgão ou entidade com a exploração da patente ou do registro. A premiação dos inventores não poderá exceder em um terço o valor das vantagens auferidas pelo órgão ou entidade com a exploração da patente ou do registro. Cabe às universidades a necessidade de estabelecer regras 
internas para a execução das medidas dispostas no decreto, assim como uma sensibilização sobre a importância das patentes no meio acadêmico (Ritter dos Santos \& Rossi, 2002:12).

Pode-se ressaltar ainda a Lei no 10.973 , de 2 de dezembro de 2004. Essa lei estabelece medidas de incentivo à inovação e à pesquisa científica e tecnológica no ambiente produtivo, com vistas à capacitação e ao alcance da autonomia tecnológica e ao desenvolvimento industrial do País, autorizando que a União, estados e municípios e as respectivas agências de fomento estimulem o desenvolvimento de projetos de cooperação entre empresas nacionais, entidades públicas voltadas à pesquisa científica e tecnológica, e organizações de direito privado sem fins lucrativos, promovendo maior integração entre as entidades públicas e a iniciativa privada.

Quanto aos fóruns de capacitação e troca de experiências entre gestores de tecnologia em instituições de ensino e pesquisa, destaca-se a REPICT (Rede de Propriedade Intelectual, Cooperação, Negociação e Comercialização de Tecnologia), que foi criada para contribuir, formular e implementar políticas de propriedade intelectual nas empresas e instituições tecnológicas, que realiza anualmente encontros de grande importância sobre o assunto (REPICT, 2004).

No que se refere aos núcleos de apoio à proteção e comercialização, as ações apoiadas pelo Fundo Verde-Amarelo devem ser enfatizadas por conceberem instrumentos para formar parcerias, multiplicar recursos e catalisar sinergias entre atores públicos e privados que integrem o sistema nacional de inovação. Esse programa estimula a interação entre universidade e empresas com vistas a apoiar à inovação (MCT, 2004).

A coleta de dados sobre o número de patentes universitárias, depositadas e concedidas, mostra-se ainda difícil. Existem vários estudos que divulgam números aproximados, revelando que estes, inicialmente, eram pouco significativos em comparação ao total das patentes depositadas. Apesar de representar a princípio um valor relativamente pequeno, recentemente pode-se observar uma tendência altista, especialmente devido ao esforço das próprias universidades. Assim, os números de pedidos de patentes depositados foram, em média, 31 entre os anos de 1990-93. No período entre 1997-99 foi de 54 (Assumpção, 2001:13), já em 2001 foram registrados 339 aplicações para patentes (Ritter dos Santos \& Rossi, 2002:16). Comparando com o total de depósitos de pedidos 
de patentes no Instituto Nacional da Propriedade Industrial (INPI) em 2001, revela-se que 5\% dessas aplicaçôes são procedentes do meio acadêmico brasileiro (INPI, 2001).

Como índice da qualidade das invenções, pode-se verificar a relação entre os pedidos de patentes depositados e as cartas-patentes expedidas, que no ano 2001 foi de 35\%, ou seja, 118 patentes concedidas (Ritter dos Santos \& Rossi, 2002:16). Pode-se constatar, portanto, que em números absolutos ainda são poucas as aplicações para patentes e as respectivas concessões no Brasil, o que é atribuído à falta de uma política de proteção do patrimônio intelectual (Latini, 2003:7), à existência de um sistema de inovação imaturo e desbalanceado e à falta de apoio governamental às universidades brasileiras, o que ganha relevância quando se compara com os números apresentados por universidades norteamericanas, o que será discutido no próximo item.

\subsection{Estados Unidos}

Com relação à legislação norte-americana referente à proteção da propriedade intelectual, já nos anos 1980 o governo dos EUA lançou um marco regulatório para apoiar a proteção legal de resultados de pesquisas universitárias, assim como a sua respectiva comercialização. Trata-se do Patent and Trademark Amendments Act, U.S.C. Public Law 96-517, também denominado BayhDole Act, ${ }^{2}$ que entrou em vigor em 1981. Com essa iniciativa, as universidades estadunidenses adquiriram o direito de se apropriarem e de comercializarem os resultados de suas pesquisas. Além disso, o Bayh-Dole Act excluiu a possibilidade de que, caso a comercialização das patentes traga lucros, estes sejam repassados ao órgão financiador por meio de restituições ou cortes nos orçamentos das universidades.

O U.S. Public Law 98-620, do ano de 1984, ainda ampliou os direitos das universidades para poderem explorar os resultados de pesquisa patenteados por meio da concessão de licenças exclusivas. Isto pode ser concebido como um fator decisivo no tocante aos impulsos às atividades de transferência baseadas em patentes e também para garantir o autofinanciamento da pesquisa e de sua respectiva proteção legal. A finalidade dessas duas legislações era limitar a influência

2 Conhecida pelo nome dos dois senadores que criaram a lei: Birch Bayh (Indiana) e Robert Dole (Kansas). 
do governo no processo de comercialização de resultados de pesquisa acadêmica, apesar destas serem publicamente financiadas, assim como incentivar as universidades para estabelecerem os respectivos escritórios de transferência de tecnologia (Henderson et al., 1998; Mowery et al., 2001).

Cabe notar que essas leis representam apenas um marco regulatório federal, que confere às universidades amplos poderes de definir a configuração interna dessa lei através de medidas próprias. Isto se manifesta na sua autonomia para experimentar regras e procedimentos explícitos sobre a reivindicação das patentes universitárias, a distribuição dos lucros auferidos pela comercialização e o estabelecimento da remuneração para os pesquisadores envolvidos na geração do conhecimento objeto de patenteamento (Henderson et al., 1998:121). De um modo geral, estes têm direito a receber entre 30\% até 50\% (Thursby et al., 2001; Assumpção, 2001); em alguns casos, ainda menos ou mais (Lach \& Schankerman, 2003) das receitas auferidas pela exploração comercial da invenção, descontando-se os custos para o patenteamento e a administração desse direito.

O patenteamento e a comercialização das invenções universitárias aumentaram de forma significativa nos EUA nos últimos 20 anos. O levantamento dos dados nesse país compete à Association of University Technology Managers (AUTM) que os divulga, desde o ano de 1991, regularmente no Licensing Survey. O número de pedidos depositados para patentes que se originam do meio acadêmico passou de 96 no ano de 1965 para cerca de 300 em 1980 (Abramson et al., 1997:102), 2.715 em 1995 e 7.921 no ano de 2003 (Stevens \& Toneguzzo, 2004:16). Ou seja, as universidades estadunidenses, no ano de 2003, contribuíam em 2,4\% no total das aplicaçôes para patentes nos EUA (USPTO, 2003:106). Um percentual que parece ser insignificante, mas que em números absolutos é muito superior ao nível internacional. À primeira vista, esse aumento pode ser concebido como uma resposta às mudanças legislativas nos anos 1980 e 1984 e também às medidas adotadas internamente pelas universidades (Link et al., 2003; Shane, 2004).

Contrariamente a essa posição, alguns estudos mostram que tais alterações tiveram pouco efeito no uso das patentes e na sua comercialização pelas universidades (Henderson et al., 1998) e que os fatores de incentivo foram as iniciativas governamentais e as decisões judiciais que reforçaram os direitos de proteção intelectual, assim como o maior fomento federal para atividades de P\&D (Jaffe, 1989; Mowery et al., 2001, 2002). 


\subsection{Alemanha}

Assim como nos Estados Unidos, o governo alemão tem realizado recentemente uma série de ações buscando incentivar a proteção legal, a transferência e a comercialização dos resultados das pesquisas desenvolvidas nas universidades. A reforma realizada no marco regulatório federal das universidades (Hochschulrahmengesetz), no ano de 1998, estabeleceu como função adicional das universidades a promoção da transferência de tecnologia e conhecimento.

Como reação à necessidade econômica da melhor utilização do sistema de patentes e às experiências bem sucedidas do Bayh-Dole Act dos EUA, no ano de 2002 foi reformulada a lei federal que regula o tratamento das invenções feitas por empregados (Gesetz über Arbeitnehmererfindungen), a qual entrou em vigor em 7 de fevereiro de 2002. Com essa lei, o privilégio dos professores titulares em possuírem todos os direitos e obrigaçōes referentes às invenções realizadas em sua função acadêmica (Hochschullehrerprivileg) foi abolido. Tal legislação estabelece que as invenções de qualquer funcionário, inclusive dos professores titulares, passam a pertencer às universidades e devem ser anunciadas dois meses antes da sua publicação para que o patenteamento pela universidade seja possível. Com essa nova situação, tornou-se factível que as universidades, em seu próprio nome, possam proteger legalmente e comercializar aqueles resultados de pesquisas que sejam economicamente viáveis. Se isto ocorre, a remuneração dos inventores universitários representa $30 \%$ da receita total gerada pela exploração da invenção patenteada.

Dentro deste contexto, o Ministério Federal da Educação e Pesquisa (Bundesministerium für Bildung, Wissenschaft, Forschung und Technologie BMBF), no ano de 2002 introduziu uma iniciativa de fomento (BMBF, 2001), limitada ao prazo de três anos, para que as universidades pudessem criar uma infra-estrutura profissional, denominada Patentverwertungsagenturen (PVA), destinada à proteção legal dos resultados de pesquisa e sua conseqüente comercialização. Após esse período, haverá uma redução gradativa do financiamento, esperando-se que esta seja compensada pelos lucros adquiridos.

Como no caso brasileiro, o mapeamento e a disponibilização de dados sobre o número de patentes procedentes das universidades alemãs não são somente incompletos, mas diferem consideravelmente nos estudos das diferentes 
instituições. Logo, pode-se efetuar apenas algumas estimações, revelando que uma média entre 2\% (Bartenbach \& Volz, 2002:743) e 4\% (Schmoch et al., 2000:24ss) das aplicações são procedentes desse setor. Esse percentual, no ano de 2003, correspondeu a um valor em torno de 1.250 e 2.500 aplicações (DPMA, 2004). Nem a TechnologieAllianz e.V., que é a associação dos 20 PVA que estão em fase de estabelecimento, nem o BMBF, os órgãos responsáveis por esse processo, publicam dados sistematizados e abrangentes. Os únicos dados disponíveis mostram que os PVA registraram 528 pedidos para patentes na primeira metade do ano de 2003 (BMBF, 2004). Isto corresponde a aproximadamente 1.000 aplicações de patentes, ou seja, 1,5\% do total das aplicações realizadas na Alemanha anualmente (DPMA, 2004). Esses números refletem o fato de que ainda existem fortes deficits no patenteamento pelas universidades alemãs e que a resposta às mudanças legislativas ainda pode ser caracterizada como modesta, talvez porque a Alemanha empreendeu-as relativamente tarde e de forma muito burocrática.

Analisadas as questões teóricas acerca das patentes e os marcos legislativos vigentes nos países objetos de estudo cabe examinar os impactos das patentes universitárias sobre as próprias universidades e sobre o setor privado para que, finalmente, sejam apontadas sugestões de políticas de estímulos às patentes no meio acadêmico.

\section{Impacto de patentes originadas nas universidades}

No que se refere às conseqüências sobre as universidades, dois aspetos se destacam: a concessão de estímulos às atividades de ensino e pesquisa orientadas para as inovações e as repercussões ao financiamento das universidades, que serão discutidas nos próximos itens.

\subsection{Conseqüências para as universidades}

\subsubsection{Ensino e pesquisa}

As universidades possuem um diferenciado conjunto de funções, no qual se destaca a formação de recursos humanos qualificados, que deveria corresponder 
ao nível atual de ciência e pesquisa por meio da contratação de professores e pesquisadores que se sobressaem. Outra função relevante é aquela que compete às universidades no marco do processo de geração de conhecimento, já que elas são, desconsiderando-se os institutos de pesquisa e as empresas, as fontes mais importantes de novos conhecimentos vindos das ciências básica e aplicada. O potencial de geração de conhecimento e tecnologia das universidades estende-se praticamente a todos os tipos de pesquisa, tanto no sentido qualitativo como também no quantitativo, devido a sua ampla infra-estrutura e capital humano. Através das mudanças legislativas referentes ao tratamento da questão das patentes nas universidades ocorridas em vários países, suas funções tradicionais foram ampliadas, passando a englobar também a proteção legal dos resultados das pesquisas comercialmente exploráveis, assim como sua transferência ao mercado.

Como a configuração das estruturas institucionais tem grande relevância para eficiência desses processos de difusão, as universidades começam a ter um papel-chave na ligação entre a pesquisa e a sua aplicação comercial. $\mathrm{O}$ cumprimento dessas funções depende não apenas da infra-estrutura disponível, como tecnologias de informação e comunicação, bibliotecas, centros de informação sobre patentes, como também dos recursos humanos existentes. Desta forma, a atuação de pessoal altamente qualificado e produtivo, em um ambiente de estímulo às atividades de pesquisa, é um fator decisivo tanto para a geração de conhecimento como para sua avaliação comercial e transposição em valores econômicos.

Disso decorre o fato de que se as universidades dispõem da possibilidade de venda ou concessão de licença de suas patentes e, se essa situação vier acompanhada da participação financeira dos inventores nos lucros gerados, estas poderão dar maiores estímulos para a publicação de conhecimento e para a realização de pesquisas que sejam comercialmente exploráveis. Além disso, serão capazes de aumentar a sua atratividade como um ambiente de trabalho para pesquisadores altamente qualificados, que busquem a solução de problemas tecnológicos. Isto ocorrerá porque, para eles, o resultado dos esforços de suas pesquisas se manifestará em uma elevação dos salários devido à comercialização das patentes. Essa concessão de estímulos econômicos pode reforçar os processos de migração entre as universidades e as empresas que 
fazem pesquisas, o que no passado funcionava melhor apenas em uma direção, ou seja, a migração do capital humano das universidades para o setor privado.

Embora, para os cientistas altamente qualificados, o ambiente de trabalho no meio acadêmico pareça ser atrativo, os salários relativamente baixos pagos pelas universidades restringem a ocorrência desses processos de migração. Sendo assim, uma participação considerável nos lucros gerados pela comercialização das patentes compensaria essa desvantagem estratégica. Adicionalmente, a remuneração para os inventores implica uma motivação adicional para que projetos de pesquisa sejam finalizados com sucesso.

Para as universidades, a exploração das invenções não implica apenas em vantagens financeiras. Por meio de parcerias e cooperações com o setor privado, elas têm acesso a um grande número de informações e a know-how adicional, o que enriquece os processos de pesquisa e de ensino nas universidades. As atividades de patenteamento e de licenciamento bem-sucedidas ao setor privado ganham importância como um indicador para avaliar a qualidade científica do trabalho dos professores e dos pesquisadores. Deste modo, as patentes funcionam como uma medida de avaliação, pois essas podem conceder informaçóes sobre o valor comercial dos resultados das pesquisas e contribuir para melhoria dos processos de alocação do capital humano. Mas é preciso ressaltar que apenas uma parte determinada desses resultados são suscetíveis à patenteabilidade ou mostram-se plausíveis segundo a concepção do mercado, como demonstrado na relação entre conhecimento e inovação à criação de valores econômicos, apresentada na Figura 1.

Para as empresas, a importância do conhecimento e tecnologia nas universidades por meio de patentes difere no que diz respeito às áreas científicas. Sendo assim, sua atratividade aumenta sobretudo em tecnologias que requerem uma pesquisa intensiva. Também as motivações dos pesquisadores e professores das universidades, no que se refere ao patenteamento, são bem diferentes. O sistema de valores presente no meio acadêmico tende a estimar mais os efeitos de reputação das publicações em jornais e revistas científicas do que o número de aplicaçôes para patentes. Isto ocorre devido às burocracias vinculadas ao processo de patenteamento, que também levam a um atraso para revelação dos resultados de pesquisas. Esses obstáculos são acrescentados pela falta de conhecimento das possibilidades de proteção e exploração da propriedade intelectual, que se deve 
ao fato de publicações científicas apresentarem relativo sucesso, independentemente da bem-sucedida comercialização dos resultados das pesquisas. Esses valores da comunidade científica influenciam na inclinação ao patenteamento e licenciamento, atuando como obstáculo à realização dessas atividades.

\subsubsection{Fonte de recursos}

As patentes significam não só um estímulo para a orientação ao ensino e à pesquisa dentro das universidades, mas também têm uma função como fonte de recursos. Neste contexto, o ponto-chave é a "livre transferibilidade" das patentes que dão razão a sua função como mecanismo de ligação entre as atividades de P\&D e a sua exploração comercial. Os efeitos da transferência de ciência e tecnologia em valores econômicos através das patentes diferem dependendo do método aplicado. Esses são os seguintes: i) concessão de licenças exclusivas ou não-exclusivas; ii) a venda de todos os direitos conferidos pela patente; iii) a cooperação e joint ventures com empresas; e iv) a introdução de patentes em empresas fundadas a partir do conhecimento e tecnologias vindos do meio acadêmico (spin offs).

Com a possibilidade de introduzir as patentes em cooperações com empresas, as universidades dispóem de uma outra alternativa para conseguir os recursos financeiros e o know-how empresarial necessário para a exploração comercial. O estímulo que as empresas possuem para tais cooperações estratégicas depende tanto do potencial de mercado esperado como da posição de monopólio conferida à universidade pela patente. Os spillovers de conhecimento que induzem essa cooperação são, em diferentes escalas, importantes para ambos os lados. Neste sentido, os estudos mostram que os estímulos das empresas para uma cooperação diminuem não só quando os spillovers são fortes, mas também quando são fracos (Audretsch, 1995:58). No entanto, as universidades, devido a sua função e concepção, são caracterizadas por motivarem fortes efeitos de spillover dos conhecimentos gerados em seu interior.

Em relação às joint ventures de pesquisa, estas podem, supondo patentes com alcances reduzidos, ser consideradas como um mecanismo para a internalização de conhecimento que provêem das atividades de P\&D. Isto gera uma melhoria da coordenação de projetos de pesquisa independentes e, ao reduzir 
as ineficiências de repetição de pesquisas que requerem maiores recursos, leva a uma melhor utilização econômica dos recursos escassos.

No caso especial dos spin offs, estes representam uma das formas mais importantes para comercializar os resultados de pesquisa acadêmica (Di Gregorio $\&$ Shane, 2003). Nesse caso, as universidades abrem mão da sua propriedade intelectual renunciando aos royalties, embora requeiram uma participação minoritária nesse processo, que geralmente é vendida após um certo período gerando lucros maiores às universidades. As experiências com essas atividades mostram que as universidades podem aumentar de forma significativa seus lucros, apesar desse tipo de comercialização implicar maiores riscos, tais como a possibilidade de falência da empresa.

O entorno das universidades aproveita consideravelmente os efeitos positivos da criação de novas empresas por meio de patentes que se manifestam na geração e manutenção de postos de trabalho, nos investimentos diretos nessa área, no aumento da arrecadação fiscal, entre outros. Além disso, os spin offs aceleram a velocidade de transposição de patentes originadas nas universidades em inovaçóes comercialmente aprovadas.

As experiências verificadas nos EUA confirmam que o estabelecimento de uma adequada estrutura para o patenteamento de resultados de pesquisa e sua transferência dura no mínimo dez anos, o que requer um financiamento antecipado e programas de fomento de longo prazo. Ademais, em alguns casos como o da legislação alemã, os direitos legais à remuneração dos inventores acadêmicos devem ocorrer independentemente das receitas geradas pela comercialização da invenção patenteada cobrirem os custos do seu desenvolvimento e patenteamento (Bartenbach \& Volz, 2002:756). Portanto, as universidades, as únicas responsáveis pela decisão sobre a configuração da forma de transferência, irão preferir tendencialmente uma rápida amortização dos custos gerados pelo patenteamento, através da concessão de licenças ou da venda da patente, ao invés de sua introdução em spin offs.

Outro impedimento ao desenvolvimento de atividades empreendedoras pelo spin offs é a premiação dos pesquisadores envolvidos na geração do conhecimento objeto de patenteamento. Esta, no caso do Brasil e da Alemanha, representa um terço e $30 \%$, respectivamente, do valor das vantagens advindo da exploração da invenção patenteada. Os estudos mostram que uma partici- 
pação alta nos royalties tem um efeito negativo na taxa de criação dos spin offs (Di Gregorio \& Shane, 2003:224-225), pois os inventores, assim como as universidades mencionadas, também irão preferir lucros calculáveis e imediatos em vez de correrem os riscos de uma participação em um spin off.

O risco empresarial de não poder gerar os lucros necessários para cobrir os custos do patenteamento, o compromisso de longo prazo dessas participaçôes nas empresas, assim como uma alta e estática remuneração dos inventores acadêmicos agem como um obstáculo ao fomento de entrepreneurship, que é politicamente desejado. Adicionalmente, a escassez de recursos financeiros nas universidades, que aumenta em períodos de recessão, influencia os tomadores de decisões, o que leva tendencialmente a um nível de investimento subótimo em spin offs universitários. Além disso, a preferência pela amortização dos custos, no curto prazo, sofre impactos também dos aspectos institucionais burocráticos das universidades. Em conseqüência, a exploração comercial das patentes através das licenças ou das vendas ainda é mais comum do que sua utilização para a criação de novas empresas (Brockhoff, 2001:10-13).

Independentemente das decisões individuais sobre o patenteamento, a comercialização das patentes significa uma ampliação das fontes de recursos das universidades pela cobrança de royalties ou venda de participaçóes. O patenteamento das invenções realizadas no meio acadêmico leva, em conseqüência, a um financiamento parcial da geração de conhecimento dentro das universidades. Além dos impactos que as patentes geradas no meio acadêmico exercem sobre as próprias universidades, cabe fazer referência também aos efeitos destas sobre o setor privado.

\subsection{Conseqüências para o setor privado}

Através das reformas das legislações dos países mencionadas no item 3, as universidades atualmente podem realizar o patenteamento das tecnologias, vindas das suas pesquisas, em seu próprio nome e por sua própria conta. Isto implica viabilidade da comercialização dessas patentes por meio de licenciamentos a empresas que se interessem pela tecnologia em questão. $O$ fator fundamental é saber se a licença confere um direito exclusivo ou não-exclusivo. No primeiro caso, a tecnologia é utilizada exclusivamente por uma empresa em um período 
de tempo limitado; já no segundo, se houver uma concessão de licença a outras empresas, estas poderão também se aproveitar da exploração comercial da tecnologia patenteada.

No nível das empresas individuais, o licenciamento reduz as expectativas de sucesso de um investimento nessa tecnologia e o valor esperado dos lucros marginais diminuem à medida que a exclusividade torna-se decrescente. Desta forma, os processos de concorrência exercem um efeito negativo quando os estímulos às inovações estão em jogo, visto que reduzem os lucros das empresas e, com isto, a disposição empresarial para realizar investimentos em P\&D (Audretsch, 1995:55). Uma análise de três universidades estadunidenses mostra que, na prática, a grande maioria das patentes universitárias é comercializada na base de licenças exclusivas (Mowery et al., 2001), o que enfatiza a necessidade de disposições legais.

As possibilidades de imposição dos direitos conferidos pelas patentes mostram tendências análogas. A manutenção jurídica dos direitos de comercialização conferidos ao proprietário das licenças depende, de forma decisiva, das expectativas de sucesso das punições impostas às infrações contra a patente. Se estas forem classificadas como pessimistas, ou se o proprietário da patente não realizar uma imposição adequada de seus direitos, as empresas não estarão dispostas a comprar uma licença ou só a comprarão por um preço muito reduzido. Tais reduções dos preços podem ser interpretadas como um prêmio contra as infrações potenciais à patente.

O fato de que a qualidade das patentes universitárias, na grande maioria, não garante uma possibilidade abrangente de imposição (Towse \& Holzhauer, 2002:xxii) representa um grave problema para as políticas de licenciamento das universidades. Na prática, pode-se freqüentemente observar estratégias por parte dos concorrentes para se desviarem de patentes de terceiros através da realização de invenções substitutas. Tal situação é reforçada pelo fato de que muitas vezes as infrações a patentes são comprováveis apenas em parte ou porque sua punição parece pouco exitosa devido à restrita formulação de suas reivindicações (Levin, 1986:199). Logo, embora as patentes representem um instrumento de proteção efetivo, não deixam de ter deficiências (Audretsch, 1995:51-54). Sendo assim, para que sejam fortalecidos os estímulos à aquisição de licenças, do ponto de vista das empresas é necessário 
uma ampliação do alcance da proteção conferida pela patente e um reforço aos efeitos de barreira contra invençôes substitutas.

Apesar desses problemas, a importância das patentes para as empresas individuais não deve ser subestimada, mas depende muito da posição que a empresa ocupa no mercado. As empresas já estabelecidas utilizam-se de patentes, principalmente em situações de concorrência com outras empresas que também possuam alto nível tecnológico (Towse \& Holzhauer, 2002:xxii). Para empresas menores, especialmente novas, as patentes muitas vezes representam uma condição prévia fundamental para realizar investimentos, de forma mais abrangente, na exploração comercial de novas tecnologias, embora estejam vinculados a maiores riscos (Scherer, 1977:394). Além disso, a garantia de uma proteção exclusiva a uma invenção assegura o financiamento da sua produção e comercialização através de créditos bancários ou participações financeiras privadas o que, quase sempre, reduz o custo do financiamento para as empresas. A aquisição de licenças deve ser bem projetada, porque a demanda individual da invenção patenteada depende da relação dos custos esperados, dos riscos de pagamentos futuros (Scherer, 1977:14-19), além de opções alternativas disponíveis para a provisão de know-how.

Desta forma, a utilização das patentes, na atualidade, difere, dependendo não só do ramo da indústria, mas também da empresa individual (Mansfield, 1986:180). Assim, tende a haver um forte estímulo para a compra ou o licenciamento de uma patente universitária nos casos em que os custos para realizar atividades própria em $\mathrm{P} \& \mathrm{D}$ são altos em relação ao tamanho do mercado esperado e, também, quando o desenvolvimento da tecnologia e sua introdução no mercado implicam em maiores riscos para as empresas. Portanto, haverá nesses casos, maiores possibilidades de comercialização bemsucedida de patentes universitárias, embora a configuração da proteção legal deva levar em consideração o interesse empresarial em um alcance mais abrangente e em um maior efeito de barreiras de proteção às patentes.

Cabe ressaltar também que a importância dos conhecimentos tecnológicos transferidos não gera repercussão na função de produção apenas para uma determinada empresa (Brockhoff, 1999:476). Na realidade, as estruturas de organização, de geração e de utilização do conhecimento nas empresas, que cada vez se tornam mais complexas, levam, por meio da formação de 
mercados internos e da dependência tecnológica no marco de cooperações, a uma delimitação decrescente do ambiente em que a empresa está inserida. Assim, os canais de transferência do conhecimento tecnológico, que devem ser adaptados às exigências específicas das atividades de $\mathrm{P} \& \mathrm{D}$, podem ser considerados como um instrumento para a otimização dos processos de difusão entre as diferentes estruturas empresariais que atuam no mercado.

Devido às condições instáveis do mercado, é difícil estabelecer uma estratégia individual de informação e aprendizagem de longo prazo para as empresas (Brockhoff, 1999:480-489). Na prática, aplicam-se combinações de diferentes elementos dessas estratégias que, além disso, devem ser adaptadas de forma regular nas estruturas de seus processos de geração e utilização de informação às mudanças de situações. Isto requer uma aplicação flexível das políticas voltadas às patentes que devem acompanhar esse processo com o cumprimento de duas exigências. A primeira, através de uma configuração do alcance do efeito de barreiras e de uma duração da patente que seja orientada à situação específica do mercado. Já a segunda, mediante uma redução dos custos de transação originados pelo patenteamento e pela exploração da patente. A evolução institucional dos sistemas internacionais de patentes confirma essa tendência, embora exista ainda a necessidade de uma maior adequação.

\section{Sugestões de políticas voltadas para as universidades}

Estas considerações deixam espaço para algumas conclusões em relação a sugestôes de políticas voltadas para as universidades em áreas de ensino e pesquisa aplicada, como também em relação a sua exploração comercial mediante a sinalização de uma política inclinada ao patenteamento e à comercialização. As universidades se apresentam como um ambiente de trabalho atrativo para pesquisadores e professores altamente qualificados e interessados na transposição ao mercado dos resultados de pesquisa. Desta forma, as universidades participam, através das economias de escopo, que ocorrem também no meio acadêmico, da produtividade do capital humano atraído. Ao mesmo tempo, a disponibilidade de patentes com uma correspondente demanda no mercado significam um instrumento adicional para a avaliação dos resultados das pesquisas no meio acadêmico que, dependendo da orientação científica das áreas 
de pesquisa, facilita esclarecimentos sobre o valor efetivo no mercado do output científico. A quantidade das patentes comercializadas relata, assim, a competência científica e a vantagem de conhecimento ou de tecnologia das universidades.

A infra-estrutura abrangente das pesquisas e os recursos múltiplos do capital humano contribuem para a diversificação das tecnologias e suas explorações, que são determinantes para o fomento dos processos de inovação no âmbito das empresas. Do ponto de vista econômico, a criação de patentes com alta exclusividade é uma condição necessária para que essas mudanças nas estruturas melhorem a alocação dos recursos no meio acadêmico. A criação de uma estrutura de informação sobre patentes e sua exploração, além de reduzir os custos de transação, representa o primeiro passo nessa direção. A publicação obrigatória como característica intrínseca do patenteamento é uma condição prévia essencial à criação de tais estruturas. Isto propicia um sistema eficiente de acesso e de distribuição de conhecimento tecnológico que facilita a utilização pelas universidades dos recursos externo gerados no âmbito das empresas. Por meio da participação institucional nas invenções de terceiros, os grupos de pesquisa nas universidades ganham uma supervisão no nível de desenvolvimento de novas tecnologias, o que possibilita a estas desenvolverem soluçóes alternativas. Ao mesmo tempo, a apresentação pública das informaçóes sobre patentes evita a repetição de invenções e sobreinvestimentos que reduzem o bem-estar social.

A definição concreta das estratégias de proteção provoca o problema fundamental de ponderação entre a concessão de estímulos suficientes em relação ao interesse individual do inventor na comercialização e os estímulos de processos de concorrência e difusão de know-how e conhecimentos tecnológico (Audretsch, 1995:67ss). A outorga de patentes fortes que pode ser conseguida por meio de pesquisas e exames rigorosos, ou através de um alcance amplo da patente definido em suas reivindicações, melhoram os estímulos econômicos para atividades de invenção. A concessão de licenças exclusivas aumenta a atratividade da utilização de patentes vindas do setor acadêmico no nível das empresas individuais. As experiências realizadas nos EUA confirmam que essa possibilidade, existente desde o ano de 1984, pode ser considerada como impulso decisivo para avivar as atividades de transferência de patentes. No entanto, mediante a exclusão de concorrentes, as patentes reduzem a eficiência estática, o que bloqueia também os processos de difusão da eficiência dinâmica. 
Neste contexto, é importante para a política de patentes das universidades respeitar o caráter sistemático do conhecimento objeto de proteção. Um grande número de desenvolvimentos tecnológicos está baseado em um estoque acumulado de conhecimentos já existentes e se realizam em passos gradativos e incrementais. Isto vem acompanhado da necessidade geral de manter publicamente disponíveis teorias e conceitos fundamentais que vêm das ciências básicas que não podem ser patenteadas. Sua disponibilidade pública é condição indispensável para as ciências aplicadas e, assim, para o progresso tecnológico (Foray, 1995:84).

Esse trade-off entre estímulos para inovações vindos das atividades inventoras e os efeitos positivos para o bem-estar causado por processos de concorrência e difusão no marco institucional requer uma alta flexibilidade do sistema de patentes. Neste sentido, o alcance dos efeitos de barreira e à duração da proteção dos direitos conferidos pelas patentes devem ser configurados para os casos individuais. Além disso, é imprescindível uma utilização responsável da margem de manobra relativa à política de patentes por parte das universidades, especialmente no que refere ao fomento politicamente desejado de atividades de entrepreneurship. A introdução de patentes fortes em spin offs ou joint ventures para o incentivo de processos de transposição ao âmbito das empresas representa uma contribuição. Independentemente disto, existe a possibilidade na maioria das legislaçóes que terceiros utilizem o conhecimento patenteado com fins não-comerciais ou de pesquisa sem a prévia autorização por parte do proprietário da patente. Como conseqüência, o patenteamento no setor acadêmico não significa uma corrida por patentes seguindo o princípio the winner takes all (Foray, 1995:95).

Em relação às opções de comercialização das patentes, as políticas das universidades, por meio de medidas adequadas, devem exercer uma influência para respeitar a sua relevância crescente nas mudanças estruturais. Tais estruturas devem ser otimizadas mediante sistemas de incentivos flexíveis e redes de contato. Ao mesmo tempo, obrigações eventuais de restituições financeiras ou cortes do orçamento pelos órgãos financiadores das universidades, no caso de comercializações bem-sucedidas, devem ser excluídos para manter o fomento institucional dessas medidas por parte das universidades. Especialmente no que se refere ao fomento de atividades de entrepreneurship, com base em patentes 
do setor acadêmico, constata-se que existem ainda certas deficiências. Isto é agravado pelo fato de que a transmissão de conhecimentos tecnológicos gerados nas universidades às estruturas industriais é comprovada como tendo efeitos positivos para o desenvolvimento regional (Henzler, 2001:125-132). Portanto, a escolha das alternativas deveria resultar na utilização de patentes para a introdução em spin off.

Finalmente, as possibilidades de participação das pessoas ligadas à pesquisa na configuração da exploração comercial de suas invenções devem ser ampliadas para reforçar os estímulos econômicos para o patenteamento do lado da oferta e para propiciar uma maior orientação às necessidades do mercado de atividades de pesquisa. Isto conseqüentemente reforça a importância das patentes para o bem-estar social, o que implica a utilização e a ampliação do patenteamento no meio acadêmico (Audretsch, 1995:68). No que se refere à demanda, se os estímulos adequados para as empresas individuais forem concedidos, haverá a orientação necessária das pesquisas universitárias em relação a procura por estas.

\section{Conclusão}

A importância das universidades para as políticas de inovação, na era de uma sociedade do conhecimento, não está só no ensino e na pesquisa, mas estende-se também à proteção legal dos resultados das pesquisas universitárias e sua transposição para valores econômicos. Neste contexto, as patentes mostram-se como um instrumento de proteção efetivo que oferece possibilidades múltiplas para a transferência de conhecimento e tecnologia.

As legislações dos países que foram objetos de análise melhoraram, nos últimos anos, o marco regulatório para a proteção e exploração comercial de invenções universitárias. Apesar disso, pode-se observar que existe ainda pouca intimidade na relação entre patentes e universidades, não somente no Brasil, mas também em países altamente desenvolvidos, como é o caso da Alemanha. As deficiências ocorrem tanto na configuração e no financiamento das estruturas institucionais das universidades responsáveis pelo patenteamento e sua exploração comercial como também na inclinação para a utilização do sistema de patentes nas universidades. 
Por fim, cabe às próprias universidades, devido ao seu novo papel no âmbito das inovações, adotarem estratégias para a proteção e exploração, como também adequadas medidas organizacionais. Para isto, torna-se imprescindível que ocorra: i) melhoria de infra-estruturas das informações sobre patentes e sua transposição ao mercado; ii) maior incorporação dos pesquisadores e professores na configuração da exploração comercial; iii) orientação das atividades de pesquisa às necessidades do mercado; iv) cooperação com empresas em áreas de P\&D intensivas; $v$ ) concessão de licenças exclusivas às empresas; $\mathrm{e}$, finalmente, vi) otimização da comercialização por meio de sistemas flexíveis de estímulos e das redes de contato.

\section{Referências bibliográficas}

Abramson, N. H.; Encarnação, J.; Reid, P. R.; Schmoch, U., Technology Transfer Systems in the United States and Germany. Lessons and perspectives, Washington: Fraunhofer Institute for Systems and Innovation Research, National Academy of Engineering, 1997.

Acs, Z. J.; Audretsch, D. B.; Feldman, M. P., "R\&D Spillovers and Recipient Firm Size", in Review of Economics and Statistics, 76 (2), p.336-340, 1994.

Adams, J., "Fundamental Stocks of Knowledge and Productivity Growth", in Journal of Political Economy, 98 (4), p.673-702, 1990.

Arrow, K., "Economic Welfare and the Allocation of Resources for Inventions, in Nelson, R. (org.), The Rate and Direction of Inventive Activity, Princeton, NJ: Princeton University Press, p.609-625, 1962.

Assumpção, E., "O Sistema de Patentes e as Universidades Brasileiras nos anos 90", http://www.inpi.gov.br (23-07-2004), 2001. 
Audretsch, D. B., "Intellectual Property Rights. New Research Directions", in Albach, H.; Rosenkranz, S. (orgs.), Intellectual Property Rights and Global Competition. Towards a new Synthesis, BerlimWZB, Berlim, p.36-76, 1995.

Bartenbach, K.; Volz, F.-E.. Erfindungen an Hochschulen - Zur Neufassung des $\$ 42$ ArbEG. Gewerblicher Rechtsschutz und Urheberrecht, p.743-758, 2002.

Basberg, B., "Patents and the Measurement of Technological Change: A Survey of Literature", in Research Policy 16, p.131-141, 1987.

Brockhoff, K., "Zur Dynamik technologischer Kompetenzen”, in: Albach, H.; Eymann, E.; Luhmer, A.; Steven, M. (orgs.), Die Theorie der Unternehmung in Forschung und Praxis, Berlim, Heidelberg; Nova York, p.475-495, 1999.

, "Die Erzeugung neuen technologischen Wissens als unternehmerische Aufgabe”, in Sadowski, D. (org.), Entrepreneurial spirits, Wiesbaden: p.5-30, 2001.

Bundesministerium für Bildung und Forschung (BMBF), 1. Förderrichtlinie des Bundesministeriums für Bildung und Forschung zur BMBF-Verwertungsoffensive - Verwertungsförderung - vom 27.7.2001, Bundesanzeiger Nr. 144 vom 4.8.2001, p.16.657, 2001.

Pressemitteilung Nr. 63 vom 25.3.2004, Studie: Deutschland baut Position bei internationalen Patenten aus, http://www.bmbf.de/press/1109.php (10.5.2004).

Deutsches Patent- und Markenamt (DPMA) (2004). Messbare Innovationen zahlreiche Patent- und Markenanmeldungen beim Deutschen Patent- und Markenamt, Pressemitteilung vom 12.03.2004, http://www.dpma.de/infos/ pressedienst/pm040312.html (17.04.2004), 2004.

Di Gregorio, D.; Shane, S., "Why do Some Universities Generate More Start-ups than Others?" in Research Policy 32, p.209-227, 2003.

Feldman, M.; Feller, I.; Bercovitz, J.; Burton, R., "Equity and the Technology Transfer Strategies of American Research Universities", in Management Science, v.48, n.1, p.105-121, 2002.

Foray, D., "Knowledge Distribution and the Institutional Infrastructure. The Role of Intellectual Property Rights", in Albach, H.; Rosenkranz, S. (orgs.), Intellectual Property Rights and Global Competition. Towards a new Synthesis, Berlim: WZB , p.77-117, 1995. 
Grupp, H.; Legler, H.; Gehrke, B.; Breitschopf, B., Zur technologischen Leistungsfähigkeit Deutschlands 2002, Bundesministerium für Bildung und Forschung (orgs.), Bonn, 2003.

Henderson, R.; Jaffe, A.; Trajtenberg, M., "Universities as a Source of Commercial Technology: A Detailed Analysis of University Patenting, 1965-1988", in Review of Economics and Statistics 80 (1), p.119-127, 1998.

Henzler, H. A., "Keimzellen des Fortschritts. Zusammenspiel von Unternehmensgründungen und Gründungsclustern", in Sadowski, D. (org.), Entrepreneurial spirits, Wiesbaden, p.123-136, 2001.

Instituto Nacional da Propriedade Industrial (INPI), Relatório de Gestão 2001, http://www.inpi.gov.br/estatistica/estatistica.htm (17.06.2004), 2003.

Jaffe, A. B. "Real Effects of Academic Research", in American Economic Review 79 (5), p.957-970. 1989.

Katz, M. L.; Shapiro, C. (1985). "Network Externalities, Competition and Compatibility", in American Economic Review 75, p.424-440, 1985.

"Technology Adoption in the Presence of Network Externalities", in Journal of Political Economy 94, p.822-841, 1986.

Klemperer, P., "How Broad Should the Scope of Patent Protection Be?", in Rand Journal of Economics 21 (1), p.113-130, 1990.

Lach, S.; Schankerman, M., Incentives and Invention in Universities, NBER Working Paper No. w9727, http://www.nber.org/papers/W9727, 2003.

Landes, W. M.; Posner, R. A., "An Economic Analysis of Copyright Law", in Journal of Legal Studies XVII (2), p.325-363, 1989.

Latini, S. A., "Invenção e Inovação Tecnológica - Uma Receita de Sucesso", Carta Mensal Rio de Janeiro 49 (580), p.3-14, 2003.

Levin, R. C., "A New Look at the Patent System", in American Economic Review 76 (2), p. 199-202, 1986.

Link, A. N.; Scott, J. T.; Siegel, D. S., "The Economics of Intellectual Property at Universities: an overview of the special issue", in International Journal of Industrial Organization, 21, p.1.217-1.225, 2003. 
Machlup, F., Die wirtschaftlichen Grundlagen des Patentrechts - 1. Teil, Gewerblicher Rechtsschutz und Urheberrecht Int., p.373-390, 473-482, 524-537, 1961.

Mansfield, E., "Patents and Innovation. An Empirical Study", in Management Science 32 (2), p.173-181, 1986.

Merges, R. P.; Nelson, R. R., "On the Complex Economics of Patent Scope", in Columbia Law Review 90 (1), p. 839-916, 1990.

Ministério da Ciência e Tecnologia (MCT), CT-FVA: Fundo Verde-Amarelo http:/ /www.mct.gov.br/Fontes/Fundos/cts/ctfva/ct_fva.htm (15.06.2005), 2004.

Mowery, D.; Nelson, R. R.; Sampat, B.; Ziedonis, A., "The Growth of Patenting and Licensing by U.S. Universities: An Assessment of the Effects of the BayhDole Act of 1980", in Research Policy 30 (1), p.99-119, 2001.

"Academic Patent Quality and Quantity Before and After the BayhDole Act in the United States", in Research Policy 31 (3), p.399-418, 2002.

Palmer, T. G., "Intellectual Property. A Non-Posnerian Law and Economics Approach", in Hamline Law Review 12 (2), p.261-304, 1989.

Polanyi, M., Personal Knowledge Towards a Post Critical Philosophy, Chicago, 1962.

Rede e Propriedade Intelectual, Negociação e Cooperação de Tecnologia (REPICT) 2004, disponível em http://www.redetec.org.br/repict/ (15.06.2005).

Ritter dos Santos, M. E.; Rossi, A. L., "Estímulo à criação e consolidação de núcleos de propriedade intelectual e transferência de tecnologia em universidades brasileiras", Relatório final da Etapa - mapeamento das instituições, Porto Alegre, 2002, disponível em http://www.tecpar.br.

Romer, P., "Increasing Returns and Long-Run Growth", in Journal of Political Economy 94 (5), p.1.002-1.037, 1986.

Scherer, F. M., "The Economic Effects of Compulsory Patent Licensing, Graduate School of Business Administration", Nova York: Center for the Study of Financial Institutions, New York University, p.5-90, 1977.

Schmoch, U.; Licht, G.; Reinhard, M., Wissens- und Technologietransfer in Deutschland, Stuttgart, 2000. 
Schumpeter, J. A., Konjunkturzyklen. Eine theoretische, historische und statistische Analyse des kapitalistischen Prozesses, Göttingen, 1961.

Shane, S., "Encouraging University Entrepreneurship? The Effect of the BayhDole Act on University Patenting in the United States", in Journal of Business Venturing 19, p.127-151, 2004.

Stevens, A. J.; Toneguzzo, F. , AUTM Licensing Survey, FY 2003 Survey Summary, Northbrook, 2004.

Thursby, J.; Kemp S., "Growth and Productive Efficiency of University Intellectual Property Licensing”, in Research Policy, 31(1), p.109-124, 2002.

Thursby, J. G.; Jensen, R.; Thursby, M.C., "Objectives, Characteristics and Outcomes of University Licensing: a survey of major U.S. universities", in Journal of Technology Transfer 26 (1-2), p.59-72, 2001.

Towse, R.; Holzhauer, R., "Introduction, The Economics of Intellectual Property I”, Cheltenham, Northampton, p. xi-xxxii, 2002.

United States Patent and Trademark Office (USPTO) Performance and Accountability Report: Fiscal Year 2003, http://www.uspto.gov/web/offices/com/ annual/2003/2003annualreport.pdf (16.8.2004), 2003. 